\title{
Identification of differentially expressed genes associated with coronary in-stent restenosis by integrated bioinformatics approaches
}

\author{
Meijuan Chen ${ }^{1}$, Yaoshan Dun ${ }^{1,2,3}$, Wenliang Zhang ${ }^{1,2}$, Suixin Liu ${ }^{1,2}$ \\ ${ }^{1}$ Division of Cardiac Rehabilitation, Department of Physical Medicine \& Rehabilitation, Xiangya Hospital of Central South University, Changsha, \\ China; ${ }^{2}$ National Clinical Research Center for Geriatric Disorders, Xiangya Hospital of Central South University, Changsha, China; ${ }^{3}$ Division of \\ Preventive Cardiology, Department of Cardiovascular Medicine, Mayo Clinic, Rochester, MN, USA \\ Contributions: (I) Conception and design: M Chen; (II) Administrative support: M Chen, S Liu, W Zhang; (III) Provision of study materials or \\ patients: M Chen; (IV) Collection and assembly of data: M Chen; (V) Data analysis and interpretation: M Chen, Y Dun; (VI) Manuscript writing: All \\ authors; (VII) Final approval of manuscript: All authors. \\ Correspondence to: Suixin Liu. Division of Cardiac Rehabilitation, Department of Physical Medicine \& Rehabilitation, Central South University, \\ Xiangya Hospital, No. 87 Xiangya Road, Changsha 410008, China. Email: liusuixin@csu.edu.cn; Wenliang Zhang. Division of Cardiac \\ Rehabilitation, Department of Physical Medicine \& Rehabilitation, Central South University, Xiangya Hospital, No. 87 Xiangya Road, Changsha \\ 410008, China. Email: zhangwenliang@csu.edu.cn.
}

Background: In-stent restenosis (ISR) is a common complication following percutaneous coronary intervention (PCI). Designing ISR-specific therapeutic targets is important for optimizing coronary stenosis therapy. This study aims to find new potential key genes related to ISR and the usefulness of differentially expressed genes (DEGs) as diagnostic biomarkers for ISR.

Methods: Microarray datasets of peripheral blood was downloaded from the Gene Expression Omnibus (GEO) public database (GSE46560, n=11). The DEGs between the ISR group and the control were obtained through the limma package analysis of the R language. Gene ontology (GO) and Kyoto Encyclopedia of Genes and Genomes (KEGG) enrichment analyses were used to obtain the related signal pathways. STRING database was used to constructed a protein-to-protein interaction network with DEGs. Networkanalyst database was used to predict the target miRNA of the target gene. The area under the curve (AUC) value obtained from receiver operating characteristic (ROC) curve analysis was used to evaluate the diagnostic effectiveness of the hub gene in distinguishing ISR patients from normal individuals.

Results: A total of 154 DEGs were identified between ISR group and control group, including 57 upregulated and 97 down-regulated DEGs. GO enrichment analysis showed that genes were enriched in homeostasis, cell morphology and cell connection. KEGG pathway analysis shows that genes are mainly involved in human papillomavirus infection, salmonella infection, human T-cell leukemia virus type 1 infection, axon guidance and MAPK signaling pathway. CLTA, CAT, STAT5A, CD300A, CA1, NCF2, HBQ1, $A H S P, S L C 4 A 1$ and EPB42 were identified as 10 hub genes. A total of 151 target miRNAs of 7 DEGs were obtained, and 149 mRNA-miRNA pairs were identified. ROC curve indicates that CA1, STAT5A and HBQ1 have high diagnostic value in ISR.

Conclusions: CA1, STAT5A and HBQ1 are identified as specific related genes for ISR patients. These genes may provide new targets for the early identification and treatment of ISR.

Keywords: In-stent restenosis (ISR); biomarker; bioinformatics analysis; differentially expressed genes

Submitted Sep 19, 2021. Accepted for publication Dec 21, 2021.

doi: 10.21037/apm-21-2681

View this article at: https://dx.doi.org/10.21037/apm-21-2681

^ ORCID: 0000-0002-5377-0557. 


\section{Introduction}

In-stent restenosis (ISR) is a common complication after percutaneous coronary intervention (PCI), which can lead to failure of stent implantation and thus always requires repeated intervention (1). ISR is defined as the entire or segmental lumen stenosis in the stent with a degree of $\geq 50 \%$, which often occurs several months after PCI (2). It is also clinically defined as the presence of recurrent angina pectoris and electrocardiograph changes indicating ischemia, requiring revascularization of the target vessel (3). Although the interventional treatment methods are constantly being updated through balloons to bare-metal stents (BMS) and then to current drug-eluting stents (DES), through which the restenosis rate has dropped from $40 \%$ to the current $5-10 \%$, the restenosis rate is still high, particularly the emergence of late or even very late stent restenosis (4-7). The incidence of very late stent-related events within 1 to 5 years after PCI for all stent types is $\sim 2 \%$ /year, which is more common in first- and secondgeneration DES compared with $\operatorname{BMS}(8,9)$. At the same time, due to the elastic shrinkage after implantation and the formation of late stenosis, the safety of the current fully degradable/absorbable DES is yet to be verified $(10,11)$.

The mechanisms relevant to ISR are as of yet ambiguous and exploration into the mechanism of restenosis in the stent is still an important issue. Various factors such as lipid metabolism disorder, formation of new atherosclerosis, chronic inflammation, arterial injury, and poor coverage of neointimal struts are involved in the process of restenosis. The implantation of BMS causes endothelial damage, which can activate endogenous and exogenous coagulation systems and releases a variety of vasoactive substances, leading to leukocyte adhesion and vascular smooth muscle proliferation, even ultimately thrombosis and vascular stenosis (12). Many traditional mechanisms of BMS-ISR pathogenesis are also applicable to DES-ISR, including biological, mechanical, and technical factors. The metal framework, drugs, and polymer films of DES can change the shear stress distribution at the implantation site, triggering intimal hyperplasia and vascular inflammation, interfering with the protective effect of endothelial cells $(13,14)$. Some drugs may promote the apoptosis of blood vessel wall cells, leading to blood stagnation, increasing thrombus, and promoting restenosis (15). Compared with BMS, the late stent failure associated with DES may be due to the formation of neoatherosclerosis in the stent and a higher incidence of stent malapposition, especially the first-generation DES (16-19). A high degree of calcification or fibrosis in the lesion and a smaller stent size may contribute to stent malapposition (20), where the stent cannot completely or uniformly expanded to the diseased blood vessel (21). The presence of $>30 \%$ uncovered stent/transverse base is closely related to the increased risk of late acquired stent thrombosis after DES (22). Neoatherosclerosis can occur several years following stent placement and is characterized by the accumulation of lipid foam macrophages in the neointima, with or without necrotic core formation, and calcification $(19,23)$. It is related to increased endothelial dysfunction and enhanced lipid diffusion.

In addition, growing evidence has shown that genetic factors and epigenetic factors are closely related to the occurrence and development of ISR (24). There may be some potential susceptibility genes mutations and certain genes may change the sensitivity to these drugs, causing drug resistance and promoting restenosis. Ma et al. (25) found that paraoxonase-1 Q192R genotype RR can predict the occurrence of stent restenosis in patients with acute coronary syndrome. Kang et al. (26) believe that ApoE gene polymorphism is closely related to the occurrence of ISR after intracranial and extracranial artery stenting, and genotype $\mathrm{E} 4 / \mathrm{E} 4$ is an independent risk factor for ISR. The meta-analysis of Wang et al. (27) showed that the insertion/ deletion polymorphism of the gene encoding angiotensinconverting enzyme was significantly associated with ISR, but Agema et al. (28) believed that it was caused by publication bias. Therefore, greater understanding of the underlying mechanism of ISR is needed.

Bioinformatics analysis is an emerging research method in clinical disease. Through exploring the structure and function information of macromolecules at the nucleic acid and protein levels, it provides us with more relevant pathway annotation information of the differential expressed genes (DEGs) in the process of disease progression.

Given the importance of genetic factors in the occurrence and development of ISR and the fact that there are no current related articles in this regard, we hypothesize that there may be some potential susceptible gene mutations, which can cause drug resistance and promote restenosis by affecting lipid metabolism, poor intimal regeneration, and even sensitivity and transportability to certain drugs. We used bioinformatics analysis methods to further explore the differentially expressed genes of ISR based on the Gene Expression Omnibus (GEO) public database, aiming to provide new ideas for the pathogenesis of ISR and explore the key genes in ISR at the molecular level. We present the 
following article in accordance with the STARD reporting checklist (available at https://apm.amegroups.com/article/ view/10.21037/apm-21-2681/rc).

\section{Methods}

\section{Microarray data acquisition}

Data with a series number of GSE46560 was downloaded from the GEO database (http://www.ncbi.nlm.nih.gov/ geo). GSE46560 was based on the GPL15207 platform (Affymetrix Human Gene Expression Array) and was a whole-genome sequencing chip data set. The chip performed a whole-blood whole-genome sequencing analysis of 11 patients, including 6 patients with negative restenosis after PCI and 5 patients with positive restenosis after PCI. The study was conducted in accordance with the Declaration of Helsinki (as revised in 2013).

\section{Data normalization and identification of DEGs}

The GSE46560 raw data file from the GEO database was downloaded through the GEOquery package (version 2.54.1) of the $\mathrm{R}$ language (version 3.6.3). We removed the probes corresponding to multiple molecules by one probe, keeping only the probe with the largest signal value when encountering the probes corresponding to the same molecule when pinning. Then, we checked the standardization of the sample through the box diagram (Figure S1A), and check the clustering between the sample groups through the principal component analysis diagram and the uniform manifold approximation and projection diagram (Figure S1B,S1C). Then, using the limma package (version 3.42.2) we analyzed the difference between the two groups with thresholds of $\mathrm{P}$ value $<0.05$ and $\mid \log _{2}$ fold change (FC) $\mid \geq 1$ (29). To visualize the results, we used the ggplot2 package (version 3.3.3) of $\mathrm{R}$ language to draw a volcano map and used the ComplexHeatmap package to draw a heat map (version 2.2.0).

\section{Gene ontology (GO) analysis and Kyoto Encyclopedia of Genes and Genomes (KEGG) patbway enrichment analysis of DEGs}

GO enrichment analysis was used to comprehensively describe the attributes of genes and gene products in organisms, including three ontologies, which describe the molecular function (MF), cellular component (CC), and biological process (BP) of the gene. KEGG pathway enrichment analysis was used to systematically analyze the metabolic pathways of gene products in cells and the functions of these gene products. The clusterProfiler package (version 3.14.3) of the $\mathrm{R}$ language was used to explore the biological significance and pathways behind DEGs and the ggplot2 package (version 3.3.3) was used for visualization. $\mathrm{P}$ value $<0.05$ was considered statistically significant.

\section{Protein-protein interaction (PPI) network construction and hub gene identification}

The online database STRING is a widely used tool that provides information about protein co-expression relationships (https://string-db.org/). To further explore the potential connections between these DEGs, all the DEGs in this study were imported into STRING for PPI analysis with a combined score $>0.4$. We then imported the calculation results of STRING into Cytoscape (version 3.7.1) for visualization and correlation analysis (30). Based on the PPI network, the cytoHubba plug-in of Cytoscape was used to identify the top 10 genes in the PPI network, and the molecular complex detection (MCODE) plugin of Cytoscape was used to screen out the most closely connected clusters with the default setting parameters.

\section{Construction of microRNA (miRNA) co-expression network}

The online database NetworkAnalyst (https://www. networkanalyst.ca/) is a miRNA database that can be used for gene network construction. We used the NetworkAnalyst database to predict the target miRNA of DEGs and used Cytoscape to visualize the miRNA coexpression network.

\section{Diagnostic value of hub genes expression in ISR}

The receiver operating characteristic (ROC) curve analysis is often used to determine the best diagnostic threshold for a diagnostic method. Generally, the Area Under the Curve (AUC) value obtained from ROC curve analysis $>0.85$ is considered to have an excellent predictive value (31). To evaluate the diagnostic value of central genes, we used the central gene expression data in 6 reference restenosis negative samples and 5 restenosis positive samples to generate a ROC curve. Use the pROC package of the $\mathrm{R}$ language for data analysis, and use the ggplot2 package for 
Table 1 Demographic information of 5 ISR samples and 6 negative controls

\begin{tabular}{lccc}
\hline Characteristics & ISR & Control & P value \\
\hline Gender & & & 1.000 \\
Female & $1(20 \%)$ & $1(17 \%)$ & \\
Male & $4(80 \%)$ & $5(83 \%)$ & \\
Age (year) & $60 \pm 11$ & $60 \pm 16$ & 0.944 \\
\hline
\end{tabular}

ISR, in-stent restenosis.

visualization.

\section{Results}

\section{Identification of DEGs related to ISR}

After screening for inclusion conditions, our study included 5 samples of post-PCI stent restenosis patients and 6 ISR negative controls from the chip data set GSE46560. There was no significant difference in demographics between the two groups (Table 1). The ISR group included 1 female and 4 males, with an average age of $60 \pm 11$ years old; the control group included 1 female and 5 males, with an average age of $60 \pm 16$ years old. Based on the previous criteria $\mathrm{P}<0.05$ and $|\log 2 \mathrm{FC}|>1$, we identified a total of 154 DEGs in ISR patients compared with negative patients, including 57 upregulated genes and 97 downregulated genes (Figure 1).

\section{Enrichment analysis of DEGs}

By using the clusterProfiler package of $\mathrm{R}$ language to perform enrichment analysis of the DEGs with Homo sapiens background, we explored the biological functions of the DEGs with GO functional analyses and KEGG pathway enrichment (Figure 2). BP analysis revealed that all DEGs were mainly involved in (GO: 0007409) axonogenesis, (GO: 0048871) multicellular organismal homeostasis, (GO: 0048732) embryonic organ development, (GO: 0048732) gland development, (GO: 0022604) regulation of cell morphogenesis (Figure 2A). CC analysis revealed that all DEGs were mainly involved in (GO: 0005924) cell-substrate adherens junction, (GO: 0005925) focal adhesion, (GO: 0030055) cell-substrate junction, (GO: 0043025) neuronal cell body, (GO: 0097060) synaptic membrane (Figure $2 B$ ). MF analysis revealed that all DEGs were mainly involved in (GO: 0001228) DNA-binding transcription activator activity, RNA polymerase II-specific,
(GO: 0046873) metal ion transmembrane transporter activity, (GO: 0022838) substrate-specific channel activity, (GO: 0005216) ion channel activity, (GO: 0022803) passive transmembrane transporter activity (Figure 2C). KEGG pathway enrichment showed that genes were mainly involved in (hsa05165) Human papillomavirus infection, (hsa05132) Salmonella infection, (hsa05166) Human T-cell leukemia virus 1 infection, (hsa04360) Axon guidance and (hsa04010) MAPK signaling pathway (Figure 2D).

\section{PPI network construction}

PPI networks among the DEGs and encoded proteins were predicted by STRING (10.5) tools online database and visualized by Cytoscape (Figure 3). Putting 154 DEGs into the STRING database, a PPI network with a required interaction score $>0.4$ was constructed with 83 nodes and 93 edges (Figure $3 A$ ). We used the cytoHubba plugin to identify hub genes, which are the most important in PPI network and may play a significant role in the pathogenesis of ISR. By intersecting the results from the five algorithms of cytohubba (including Degree, Maximum Neighborhood Component, Maximal Clique Centrality, Density of Maximum Neighborhood Component, and Clustering Coefficient), 10 hub genes were identified: CLTA, CAT, STAT5A, CD300A, CA1, NCF2, HBQ1, AHSP, SLC4A1 and EPB42 (Figure 3B). Detailed information on these were shown in Table 2. The MCODE plugin was used to identify gene cluster modules and we identified 6 modules in this network according to the filter criteria. Cluster 1 has the highest cluster score (score: 4.5, 5 nodes and 9 edges) (Figure 3C), followed by cluster 2 (score: $3.3,4$ nodes and 5 edges) (Figure 3D), cluster 3 (score: 3.0, 3 nodes and 3 Edges) (Figure $3 E$ ), cluster 4 (score: 3.0, 3 nodes and 3 edges) (Figure $3 F$ ), cluster 5 (score: $3.0,3$ nodes and 3 edges) (Figure 3G), and cluster 6 (score: 2.8, 6 nodes and 7 side) (Figure 3H).

\section{Prediction of target miRNAs and construction of the co- expressed network}

The Networkanalyst database is an online visual analysis platform that can perform gene expression analysis and Meta analyses (https://www.networkanalyst.ca/), and can also be used to predict the target miRNA of target genes. Putting the 10 DEGs into networkanalyst, we obtained 151 target miRNAs of 7 specifically expressed hub genes, 


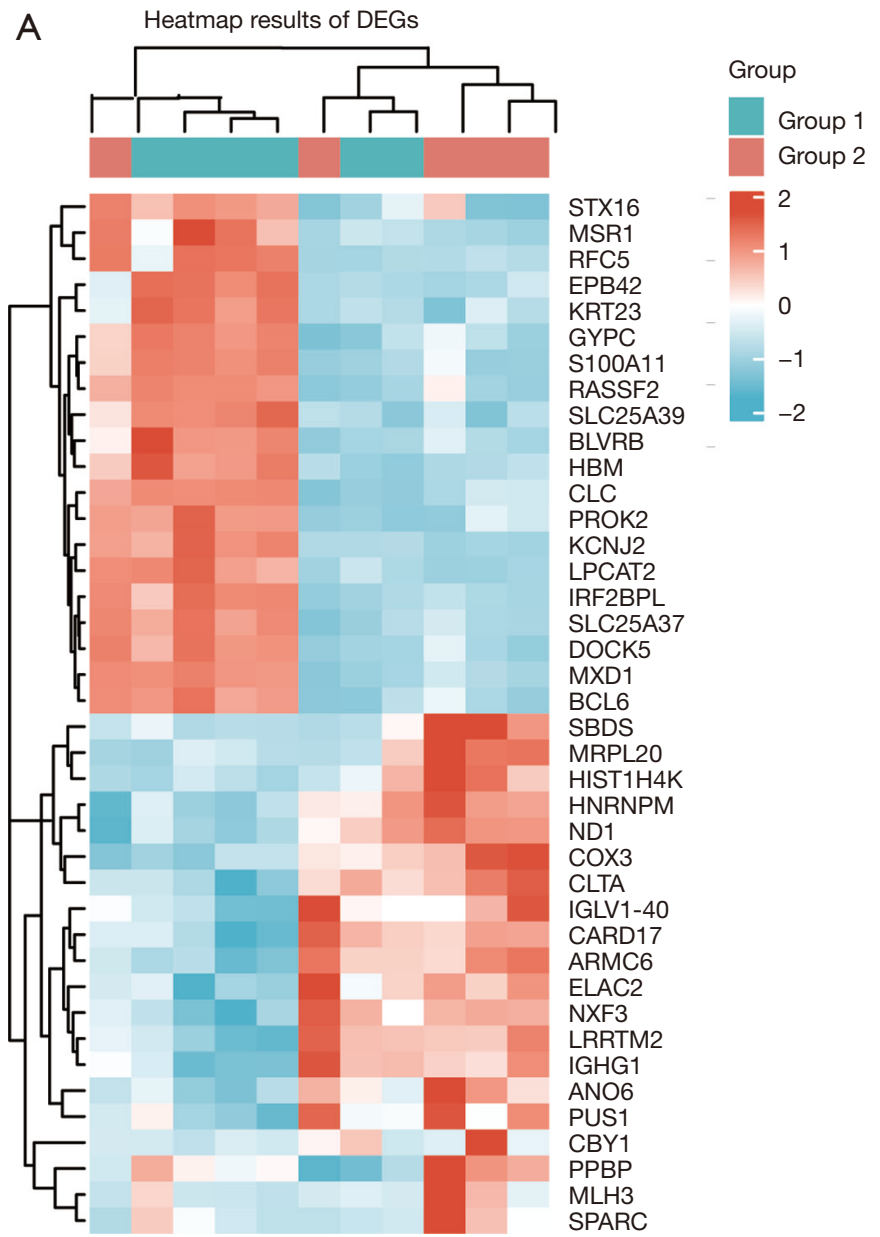

B

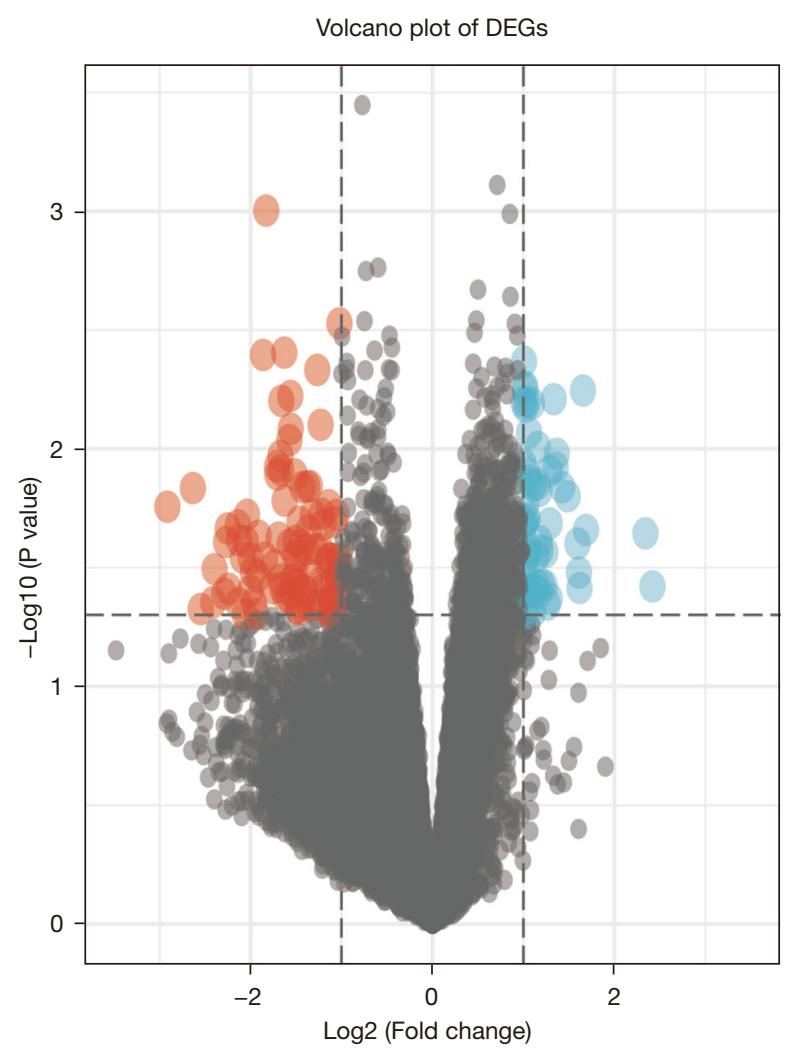

Figure 1 Heatmap and Volcano plot of DEGs. Heatmap results of top 20 genes with high and low expression in DEGs between ISR patients and negative patients (A). Volcano plot of DEGs that are different expressions between ISR patients and negative patients (B). Red dots: upregulated genes; blue dots: downregulated genes; grey dots: Undifferentiated genes. DEGs, differentially expressed genes; ISR, instent restenosis.

and identified 149 mRNA-miRNA pairs. According to the prediction results, Cytoscape constructed a mRNA and miRNA co-expression network composed of 151 nodes and 149 edges (Figure 4). SLC4A1 had the most target miRNA, reaching 61, while $C A 1$ and NCF2 had only one target miRNA respectively.

\section{Diagnostic significances of hub genes}

To assess the diagnostic value of hub genes, we analyzed the expression profiles of 10 hub genes and generated an AUC of ROC curves. Compared with negative samples, all these 10 central genes except SLC4A1 (AUC of 0.767) (Figure S1D) had excellent diagnostic value in ISR samples. The AUC in
CA1 is 0.967 (95\% CI: 0.874 to 1.000 ) (Figure $5 A$ ); the AUC in STATSA was 0.933 (95\% CI: 0.780 to 1.000 ) (Figure 5B); the AUC in $H B Q 1$ is 0.867 (95\% CI: 0.637 to 1.000 ) (Figure 5C); the AUC in AHSP is 0.833 (95\% CI: 0.557 to 1.000) (Figure 5D); the AUC in CLTA is 0.833 (95\% CI: 0.575 to 1.000 ) (Figure $5 E$ ); the AUC in EPB42 is 0.833 (95\% CI: 0.575 to 1.000 ) (Figure $5 F$ ); the AUC in NCF2 is 0.833 (95\% CI: 0.557 to 1.000 ) (Figure $5 G$ ); the AUC in $C A T$ is 0.800 (95\% CI: 0.506 to 1.000 ) (Figure $5 H$ ); the AUC in CD300A is 0.800 (95\% CI: 0.505 to 1.000 ) (Figure $5 I$ ). Given that ROC curve analysis $>0.85$ is considered to have excellent predictive value, CA1, STATSA and $H B Q 1$ appear to be the most important biomarkers for ISR among these ten genes. Among them, $C A 1$ has the 
A

GO biological process enrichment

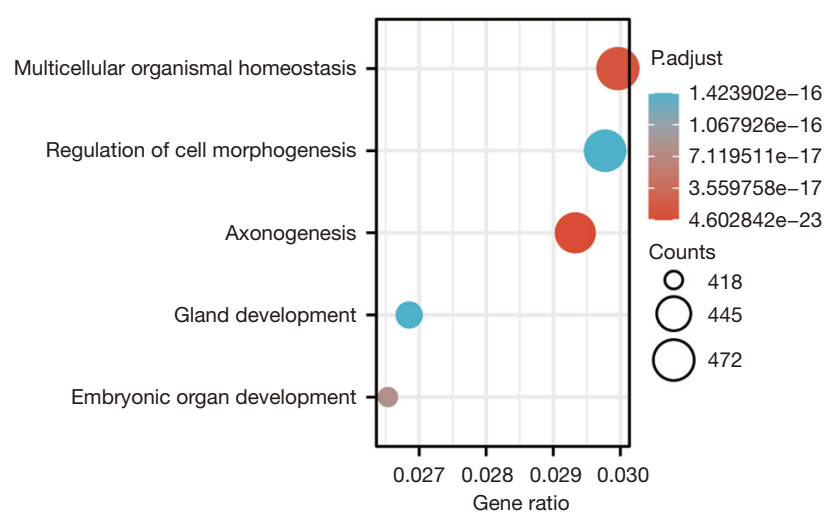

C

GO molecular function enrichment

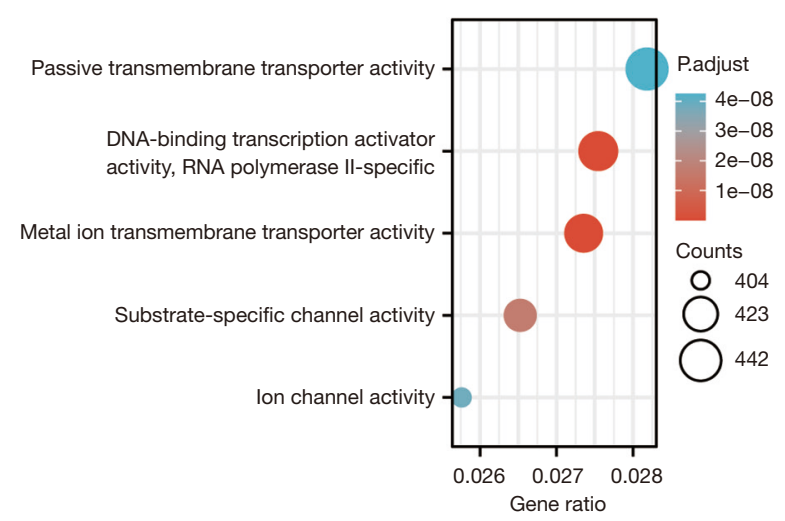

B

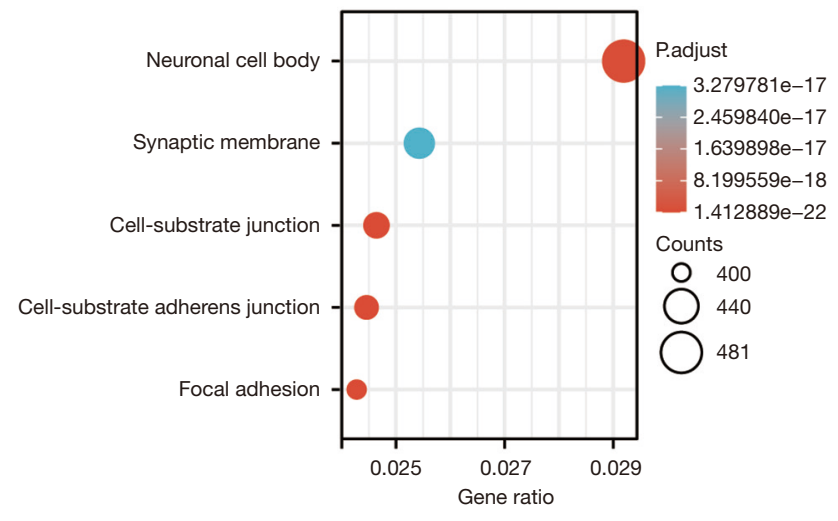

D

KEGG pathway enrichment

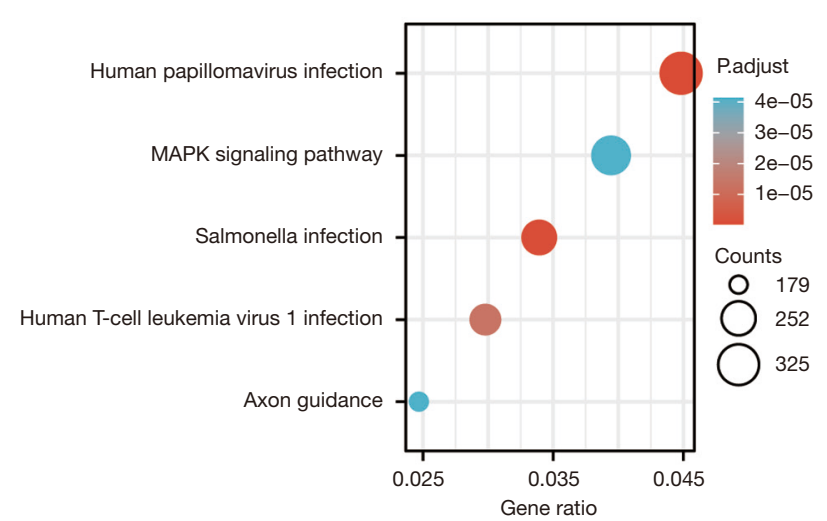

Figure 2 GO and KEGG analysis results of DEGs. GO biological process enrichment result (A). GO cell component enrichment results (B). GO molecular function enrichment results (C). KEGG pathway enrichment results (D). GO, gene ontology; KEGG, Kyoto encyclopedia of genes and genomes; MAPK, mitogen-activated protein kinase.

highest diagnostic value.

\section{Discussion}

Based on the analysis of the GEO database, we selected the genetic data set GSE46560 in GPL15207 and explored the genetic mechanism in ISR. The peripheral blood samples of patients with ISR after PCI were used as the experimental group, and the stenosis negative samples were used as the control. One hundred and fifty-four differential genes were obtained. GO enrichment analysis shows that genes are enriched in homeostasis, cell morphology, and cell connection. KEGG analysis of these candidate genes mainly focused on the signal transduction pathway of Human papillomavirus infection, Salmonella infection,
Human T-cell leukemia virus 1 infection, Axon guidance and MAPK signaling pathway. The PPI network was constructed through STRING, and 10 hub genes were obtained through Cytoscape, respectively were CLTA, CAT, STAT5A, CD300A, CA1, NCF2, HBQ1, AHSP, SLC4A1 and $E P B 42$.

CA1, STAT5A, NCF2, CAT and CD300A are closely related to ISR, and recent studies have made an effort to explore the role of these genes in ISR. CA1 is a member of the carbonic anhydrase family. It can reversibly catalyze the hydration of $\mathrm{CO}_{2}$ to form $\mathrm{HCO}_{3}^{-}$, and then quickly combine with calcium ions to form calcium carbonate, which directly participates in the calcification process and promote calcium phosphate mineralization (32). Also, it can participate in the calcification process through its effect on $\gamma$-glutamyl 


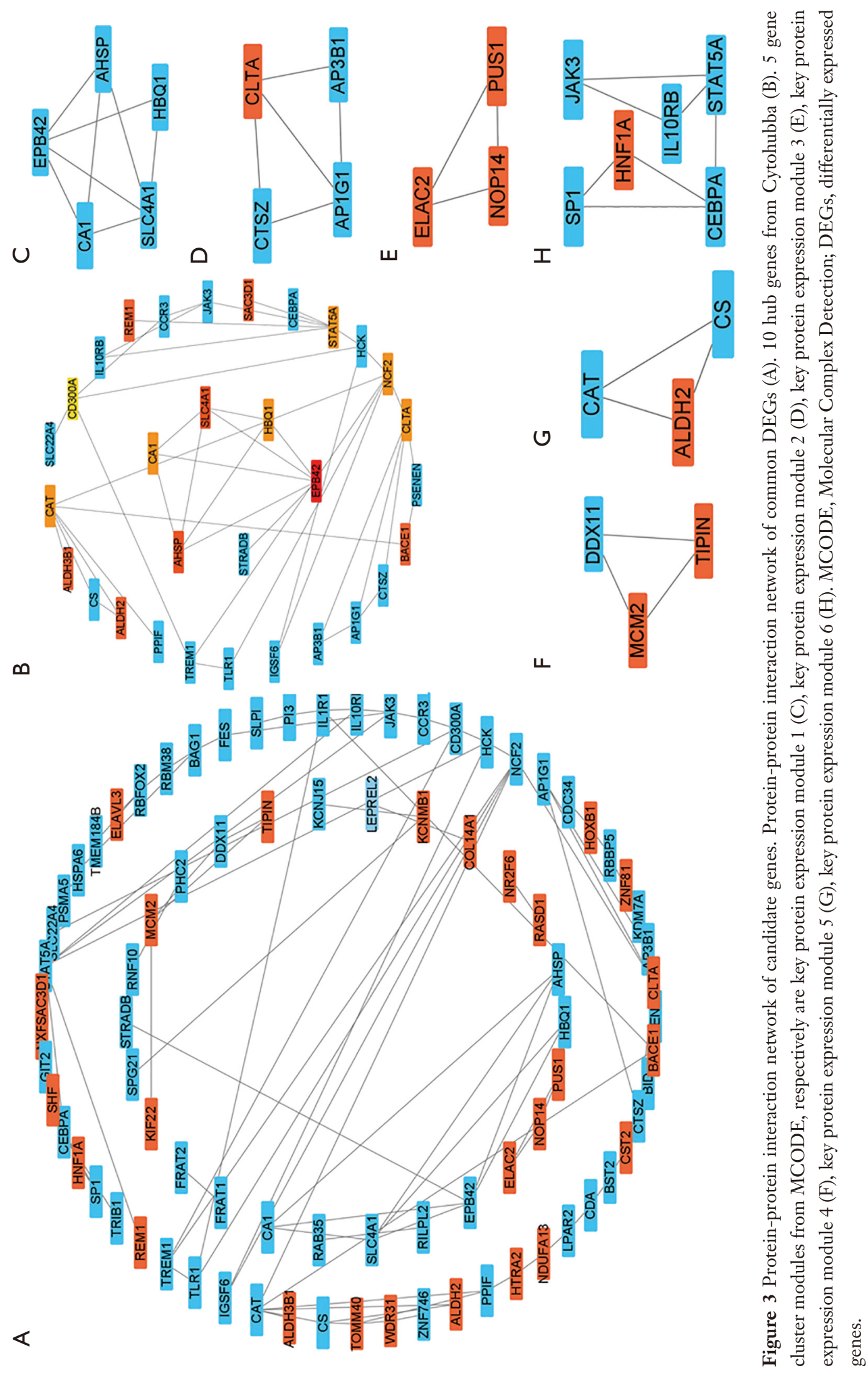


Table 210 hub genes identified by five algorithms of cytoHubba

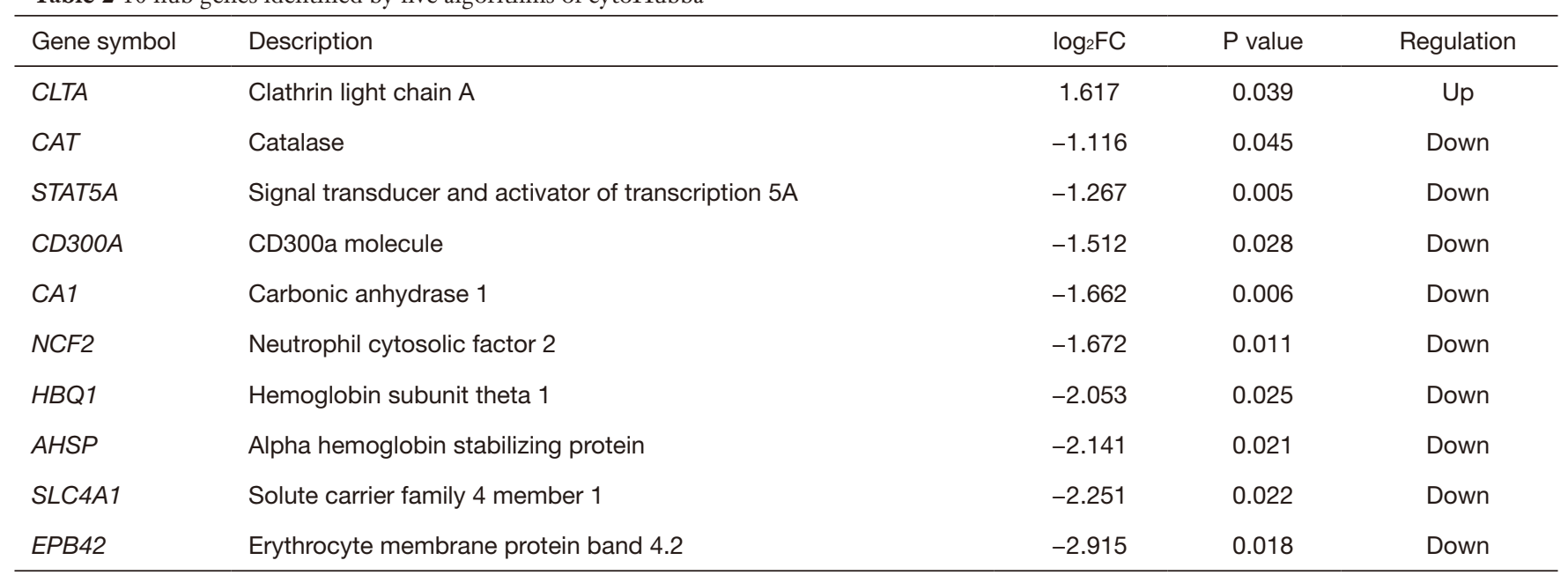

FC, fold change.

carboxylase. Arterial calcification is an active, cellregulated process that occurs in the process of osteogenesis, including the conversion of vascular smooth muscle cells to osteoblasts and the crystallization and precipitation of hydroxyapatite salts, which may cause poor coverage and delayed healing in a stent (21). In human tissue, carbonic anhydrase can stimulate vascular calcification through $C A 1$, which is related to atherosclerosis plaque formation (33). STATSA is a member of the signal transducer and activator of transcription (STAT) family, which can be activated by the phosphorylation of key tyrosine residues by Janus kinase after binding to the receptor. The activated STAT binds to a specific DNA sequence, called Interferon-Gamma Activated Sequence, and initiates the transfer of target genes (34). STAT5 can regulate the expression of genes encoding proteins that are involved in cell proliferation, differentiation, angiogenesis, inflammation, apoptosis, extracellular matrix composition and cell signal transduction. Our results showed that $S T A T S A$ expression decreased in the ISR group. The role of STATSA low expression in the occurrence and development of ISR is still controversial and there is no relevant literature to fully confirm it (35-37). However, in the cardiovascular system, STAT5 can mediate vascular endothelial morphogenesis induced by fibroblast growth factor (38). Endothelial cells stimulated by inflammation can down-regulate some post-transcriptional regulatory factors, such as miR-221/222, which targets STAT5A to negatively regulate vascular remodeling (39). Ischemia/reperfusion injury after PCI increases the levels of cardiac hypoxia-inducible factor- 1 and interleukin-10 proteins, activating AKT, phosphatidylinositol 3 kinase and vascular endothelial growth factor (40). STAT5A plays a protective role in this process, and this protection role will be lost in the absence of STATSA. NCF2 can encode p67phox, which is a component of NADPH oxidase, expressed on leukocytes, endothelial cells, and aortic adventitia fibroblasts (41). Mutations in NCF2 can lead to chronic granulomatous disease, which is characterized by abnormal activity of the NADPH oxidase complex, with reduced production of reactive oxygen species (ROS) and excessive inflammation (42). NCF2 is presumed to be related to carotid plaque and may be related to unstable atherosclerotic rupture $(43,44)$. In view of the importance of NADPH oxidase in cardiovascular diseases, it is speculated that NCF2 also plays an important role in ISR, but more literature support is needed. CAT is the most abundant antioxidant enzyme ubiquitous in the human body and the most effective catalyst for the decomposition of $\mathrm{H}_{2} \mathrm{O}_{2}$. We found catalase decreased in the ISR group. As reported, coronary interventions, such as balloon angioplasty and BMS and DES implantation, can increase vascular oxidative stress through cytoplasmic Nox2, eNOS uncoupling and mitochondrial dysfunction $(45,46)$. The excessively increased ROS induces the proliferation and migration of vascular smooth muscle cells and fibroblasts, leading to neointimal growth and restenosis (12). Proliferative neointimal cells can also produce ROS, which further enhances oxidative stress and leads to endothelial dysfunction. Therefore, the decrease of catalase is closely related to the occurrence of ISR. 


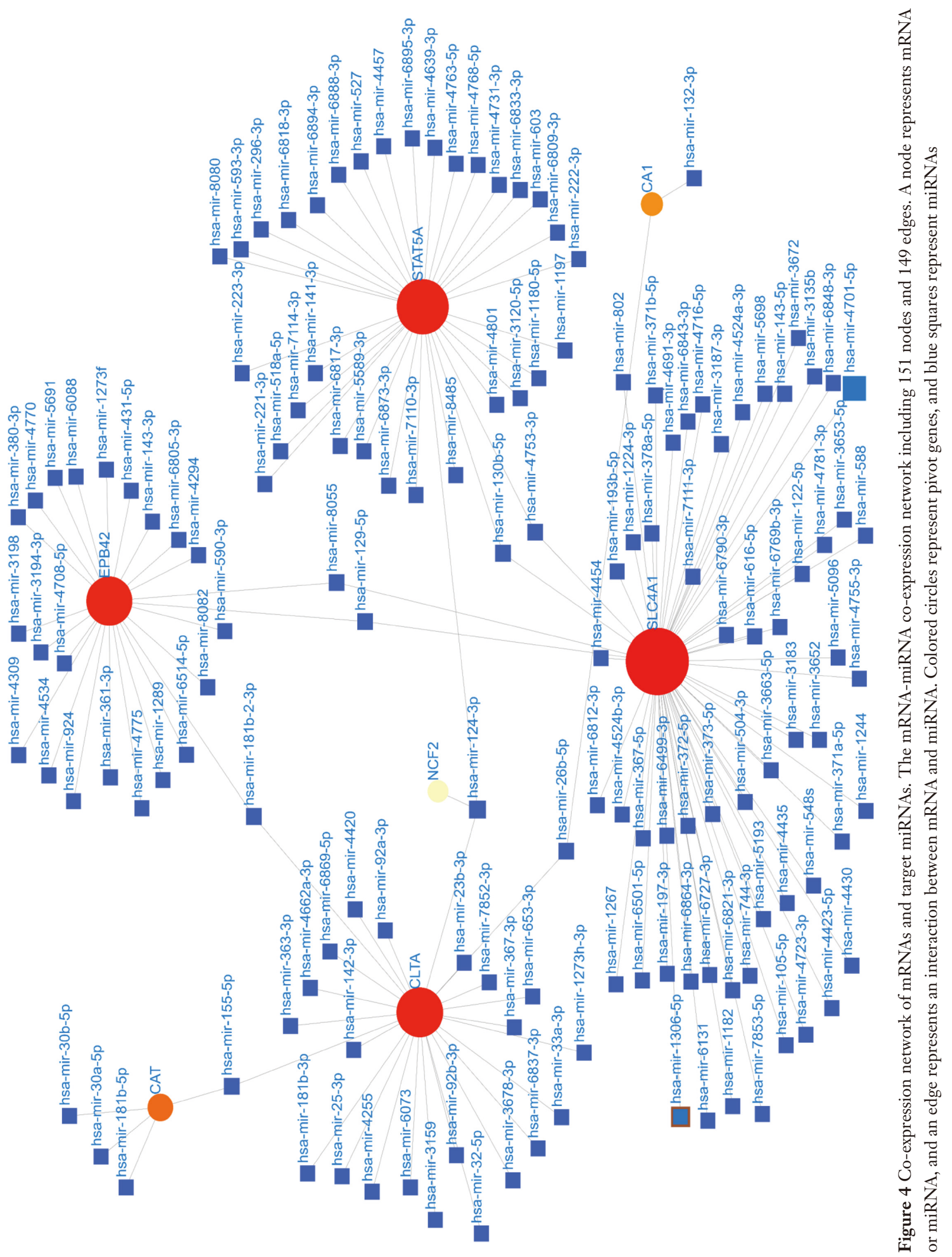


A

CA1

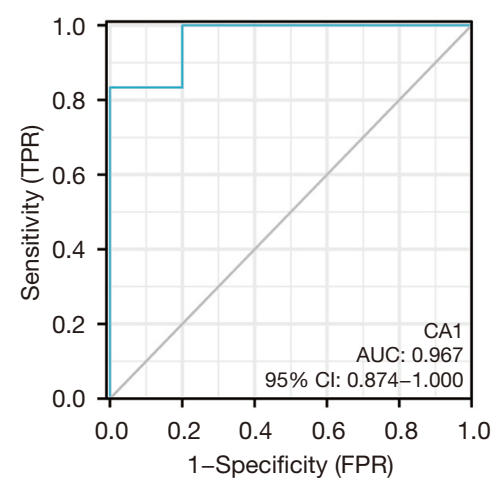

D

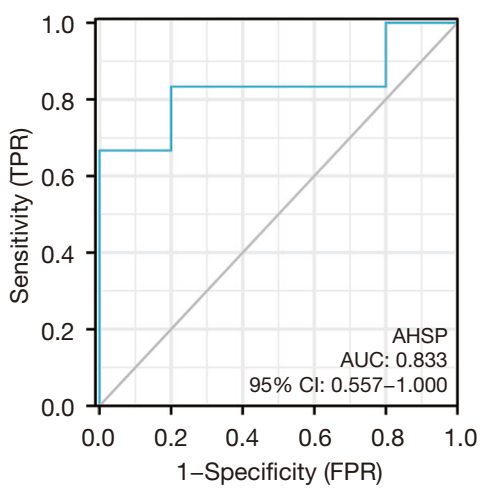

G

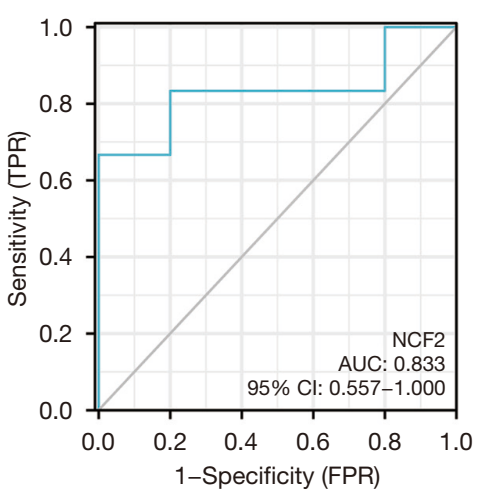

B

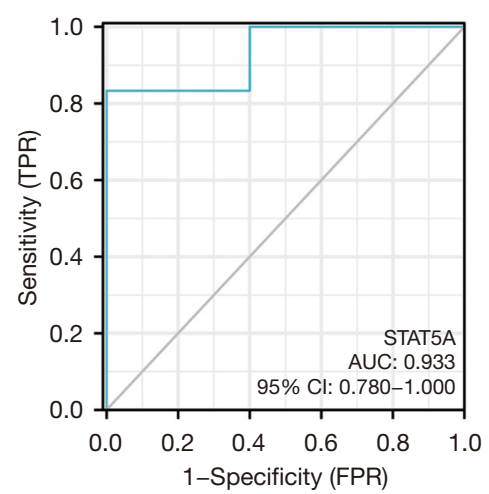

E

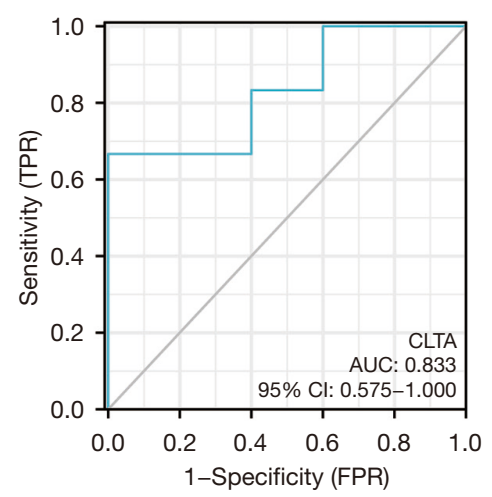

$\mathrm{H}$

CAT

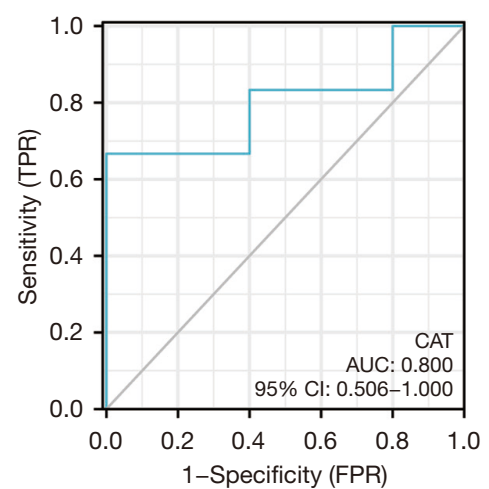

C

HBQ1

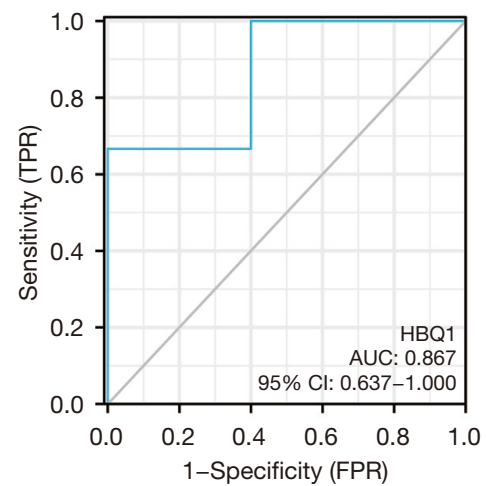

F

EPB42

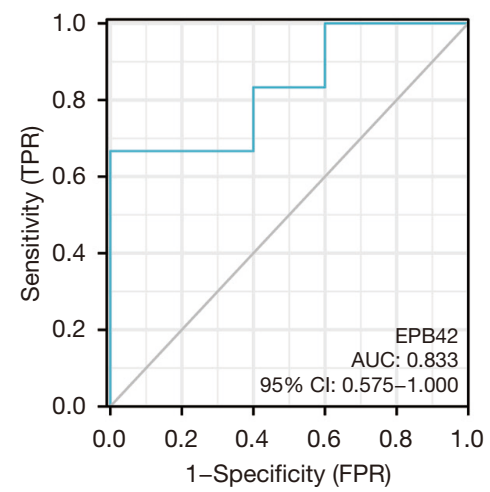

I

CD300A

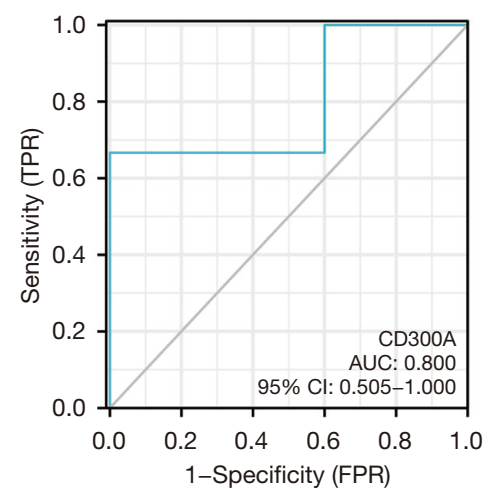

Figure 5 Diagnosis value of 9 specifically expressed hub genes in discriminating ISR patients from negative patients. CA1 (A), STAT5A (B), HBQ1 (C), AHSP (D), CLTA (E), EPB42 (F), NCF2 (G), CAT (H) and CD300A (I). AUC, area under the curve; CI, confidence interval; ISR, in-stent restenosis. 
CD300A is a molecule containing an immunoreceptor tyrosine inhibitory motif, belonging to the CD300 family of paired activation/inhibitory receptors. By binding to phosphatidylethanolamine and phosphatidylserine, CD300A can regulate the phagocytosis of dead cells (47) and deliver inhibitory signals in mast cells to inhibit the production of inflammatory cytokines and chemokines induced by lipopolysaccharide (48). The down-regulation of $C D 300 \mathrm{~A}$ may be related to persistent inflammation in ISR.

HBQ1, AHSP, CLTA, EPB42, SCL4A1 may be involved in the occurrence and development of ISR, but there is still a lack of research in this area. Based on existing research, these genes are involved in the composition, maturation, stability, cell transport and diffusion of hemoglobin and red blood cells. For instance, $H B Q 1$ is one of the components of hemoglobin (49), $E P B 42$ is a kind of red blood cell membrane protein (50), AHSP is a red blood cell-specific chaperone protein (51-53), SLC4A1 is an anion exchanger of red blood cell plasma membrane (54). The differential expression of these genes may increase the viscosity of whole blood by increasing the number of red blood cells and reducing the deformability of blood cells. Deficiency expression in EPB42 and SLC4A1 has been shown to cause hereditary spherocytosis $(50,55)$. Increased blood viscosity will increase blood flow resistance and slow flow speed, leading to ischemia, hypoxia, and accumulation of various metabolites in the tissue, which may also be one of the mechanisms leading to ISR. These genes, however, may play a pathogenic role by affecting substances transfer signal transduction that related to ISR. CLTA is one of the clathrin light chains, which participates in cell proliferation and migration, and mediates cell endocytosis (56). Impaired clathrin integrity may increase the occurrence of ISR by mediating macrophages' endocytosis and clearance of lipids (57). The down-regulation of some hemoglobinrelated genes, such as $A S H P$ and $E P B 42$, may be related to hemoglobin destruction and iron metabolism disorders, and is related to Parkinson's disease (58). The iron metabolism disorder is strongly associated to atherosclerosis, which may be involved in the formation of new atherosclerosis and eventually lead to the appearance of ISR (59). Finally, previous literature has exposed that low expression of EPB42 in pancreatic cancer is associated with poor prognosis (60). $H B Q 1$ is related to the abnormal metabolism of gastric cancer cells (61). The occurrence of tumors is closely related to the abnormal proliferation of cells. Therefore, we consider that the down-regulation of EPB42 and $H B Q 1$ may participate in the occurrence of ISR by causing excessive cell proliferation.

This research still has the following shortcomings. Firstly, the experimental sample we used is too small, and an appropriately increased experimental sample may increase the reliability of the experimental results. As a small sample size study, we have included as many patients as possible in order to improve the reliability of statistics. Under this limitation, the sex ratio between the control group and the experimental group may not be the same, although there was no statistical difference. Despite the follow-up of large clinical trials, no sex differences in the occurrence of major adverse cardiovascular events after stent placement have been observed, whether it is a drug-eluting stent (62) or the current bioresorbable vascular scaffolds (63). Secondly, no other ISR-related peripheral blood gene data sets have been found, and we cannot perform verification in multidatabase or multi-gene set. Finally, under the limitation of clinical data sources, we have not yet done the validation experiment of hub genes, including the detection of hub gene expression in peripheral blood samples of ISR patients and construction of ISR-related cell and animal models. It would be more convincing to analyze the knockout of specific genes. Changes in epigenetics also need to be considered. Due to the limited analysis methods of bioinformatics, we can only make reasonable assumptions for the reasons for the inconsistent gene expression levels of ISR.

In conclusion, our study explored the genetic and molecular effects of related genes in patients with ISR by using bioinformatics analysis methods. The results provided new insights into the molecular mechanisms of ISR patients, CA1, STATSA and HBQ1 were determined as the relevant biomarkers of the disease.

\section{Acknowledgments}

We acknowledge the GEO database for providing their platforms and contributors for uploading their meaningful datasets. We really appreciate Sharma Y, Patyar RR, Trivedi AC, Kumar S, who participated in the collection of data GSE46560, and we appreciate the 11 patients who participated in the study. We really appreciate Jeffrey $W$ Ripley-Gonzalez for polishing our manuscript.

Funding: This work was supported by grants from the National Nature Science Foundation of China (No. 82002403); Hunan Provincial Nature Science Foundation 
of China (No. 2021JJ40981); and the Youth Science Foundation of Xiangya Hospital (No. 2019Q03) to YD.

\section{Footnote}

Reporting Checklist: The authors have completed the STARD reporting checklist. Available at https://apm.amegroups. com/article/view/10.21037/apm-21-2681/rc

Data Sharing Statement: Available at https://apm.amegroups. com/article/view/10.21037/apm-21-2681/dss

Peer Review File: Available at https://apm.amegroups.com/ article/view/10.21037/apm-21-2681/prf

Conflicts of Interest: All authors have completed the ICMJE uniform disclosure form (available at https://apm. amegroups.com/article/view/10.21037/apm-21-2681/coif). The authors have no conflicts of interest to declare.

Ethical Statement: The authors are accountable for all aspects of the work in ensuring that questions related to the accuracy or integrity of any part of the work are appropriately investigated and resolved. The study was conducted in accordance with the Declaration of Helsinki (as revised in 2013).

Open Access Statement: This is an Open Access article distributed in accordance with the Creative Commons Attribution-NonCommercial-NoDerivs 4.0 International License (CC BY-NC-ND 4.0), which permits the noncommercial replication and distribution of the article with the strict proviso that no changes or edits are made and the original work is properly cited (including links to both the formal publication through the relevant DOI and the license). See: https://creativecommons.org/licenses/by-nc-nd/4.0/.

\section{References}

1. Moussa ID, Mohananey D, Saucedo J, et al. Trends and Outcomes of Restenosis After Coronary Stent Implantation in the United States. J Am Coll Cardiol 2020;76:1521-31.

2. Dangas GD, Claessen BE, Caixeta A, et al. In-stent restenosis in the drug-eluting stent era. J Am Coll Cardiol 2010;56:1897-907.

3. Kuntz RE, Baim DS. Defining coronary restenosis. Newer clinical and angiographic paradigms. Circulation
1993;88:1310-23.

4. Torrado J, Buckley L, Durán A, et al. Restenosis, Stent Thrombosis, and Bleeding Complications: Navigating Between Scylla and Charybdis. J Am Coll Cardiol 2018;71:1676-95.

5. Bhatt DL. Percutaneous Coronary Intervention in 2018. JAMA 2018;319:2127-8.

6. Eltchaninoff H, Koning R, Tron C, et al. Balloon angioplasty for the treatment of coronary in-stent restenosis: immediate results and 6-month angiographic recurrent restenosis rate. J Am Coll Cardiol 1998;32:980-4.

7. Cassese S, Byrne RA, Tada T, et al. Incidence and predictors of restenosis after coronary stenting in 10 004 patients with surveillance angiography. Heart 2014;100:153-9.

8. Madhavan MV, Kirtane AJ, Redfors B, et al. Stent-Related Adverse Events $>1$ Year After Percutaneous Coronary Intervention. J Am Coll Cardiol 2020;75:590-604.

9. Habara S, Kadota K, Shimada T, et al. Late Restenosis After Paclitaxel-Coated Balloon Angioplasty Occurs in Patients With Drug-Eluting Stent Restenosis. J Am Coll Cardiol 2015;66:14-22.

10. Alfonso F, Cuesta J. Bioresorbable Vascular Scaffolds Restenosis: Pathophysiology and Predictors. JACC Cardiovasc Interv 2017;10:1828-31.

11. Ortega-Paz L, Brugaletta S, Sabaté M. Very-late restenosis of a magnesium-based resorbable scaffold. Eur Heart J 2020;41:2602.

12. Juni RP, Duckers HJ, Vanhoutte PM, et al. Oxidative stress and pathological changes after coronary artery interventions. J Am Coll Cardiol 2013;61:1471-81.

13. Woods TC, Marks AR. Drug-eluting stents. Annu Rev Med 2004;55:169-78.

14. Inoue T, Croce $\mathrm{K}$, Morooka $\mathrm{T}$, et al. Vascular inflammation and repair: implications for re-endothelialization, restenosis, and stent thrombosis. JACC Cardiovasc Interv 2011;4:1057-66.

15. Spadaccio C, Antoniades C, Nenna A, et al. Preventing treatment failures in coronary artery disease: what can we learn from the biology of in-stent restenosis, vein graft failure, and internal thoracic arteries? Cardiovasc Res 2020;116:505-19.

16. Lee SY, Ahn JM, Mintz GS, et al. Ten-Year Clinical Outcomes of Late-Acquired Stent Malapposition After Coronary Stent Implantation. Arterioscler Thromb Vasc Biol 2020;40:288-95.

17. Yamaji K, Ueki Y, Souteyrand G, et al. Mechanisms of Very Late Bioresorbable Scaffold Thrombosis: The 
INVEST Registry. J Am Coll Cardiol 2017;70:2330-44.

18. Park SJ, Kang SJ, Virmani R, et al. In-stent neoatherosclerosis: a final common pathway of late stent failure. J Am Coll Cardiol 2012;59:2051-7.

19. Moriyama N, Shishido K, Tanaka Y, et al. Neoatherosclerosis 5 Years After Bioresorbable Vascular Scaffold Implantation. J Am Coll Cardiol 2018;71:1882-93.

20. Hong MK, Mintz GS, Lee CW, et al. Late stent malapposition after drug-eluting stent implantation: an intravascular ultrasound analysis with long-term follow-up. Circulation 2006;113:414-9.

21. Torii S, Jinnouchi H, Sakamoto A, et al. Vascular responses to coronary calcification following implantation of newergeneration drug-eluting stents in humans: impact on healing. Eur Heart J 2020;41:786-96.

22. Finn AV, Joner M, Nakazawa G, et al. Pathological correlates of late drug-eluting stent thrombosis: strut coverage as a marker of endothelialization. Circulation 2007;115:2435-41.

23. Nakazawa G, Otsuka F, Nakano M, et al. The pathology of neoatherosclerosis in human coronary implants bare-metal and drug-eluting stents. J Am Coll Cardiol 2011;57:1314-22.

24. Yang X, Yang Y, Guo J, et al. Targeting the epigenome in in-stent restenosis: from mechanisms to therapy. Mol Ther Nucleic Acids 2021;23:1136-60.

25. Ma W, Liang $Y$, Zhu J, et al. Relationship of paraoxonase-1 Q192R genotypes and in-stent restenosis and re-stenting in Chinese patients after coronary stenting. Atherosclerosis 2016;251:305-10.

26. Kang Z, Cao Y, Li L, et al. The Association Between Apolipoprotein E Gene Polymorphism and In-Stent Restenosis After Extracranial and Intracranial Artery Stenting. J Stroke Cerebrovasc Dis 2021;30:105424.

27. Wang S, Dai Y, Chen L, et al. Genetic polymorphism of angiotensin converting enzyme and risk of coronary restenosis after percutaneous transluminal coronary angioplasties: evidence from 33 cohort studies. PLoS One 2013;8:e75285.

28. Agema WR, Jukema JW, Zwinderman AH, et al. A meta-analysis of the angiotensin-converting enzyme gene polymorphism and restenosis after percutaneous transluminal coronary revascularization: evidence for publication bias. Am Heart J 2002;144:760-8.

29. Yu G, Wang LG, Han Y, et al. clusterProfiler: an R package for comparing biological themes among gene clusters. OMICS 2012;16:284-7.

30. Szklarczyk D, Gable AL, Lyon D, et al. STRING v11: protein-protein association networks with increased coverage, supporting functional discovery in genome-wide experimental datasets. Nucleic Acids Res 2019;47:D607-13.

31. Metz CE. Basic principles of ROC analysis. Semin Nucl Med 1978;8:283-98.

32. Adeva-Andany MM, Fernández-Fernández C, SánchezBello R, et al. The role of carbonic anhydrase in the pathogenesis of vascular calcification in humans. Atherosclerosis 2015;241:183-91.

33. Yuan L, Wang M, Liu T, et al. Carbonic Anhydrase 1-Mediated Calcification Is Associated With Atherosclerosis, and Methazolamide Alleviates Its Pathogenesis. Front Pharmacol 2019;10:766.

34. Hennighausen L, Robinson GW. Interpretation of cytokine signaling through the transcription factors STAT5A and STAT5B. Genes Dev 2008;22:711-21.

35. Yang X, Qiao D, Meyer K, et al. Angiogenesis induced by signal transducer and activator of transcription $5 \mathrm{~A}$ (STAT5A) is dependent on autocrine activity of proliferin. J Biol Chem 2012;287:6490-502.

36. Li Y, Zhao Y, Peng H, et al. Histone Deacetylase Inhibitor Trichostatin A Reduces Endothelial Cell Proliferation by Suppressing STAT5A-Related Gene Transcription. Front Oncol 2021;11:746266.

37. Bucher F, Lee J, Shin S, et al. Interleukin-5 suppresses Vascular Endothelial Growth Factor-induced angiogenesis through STAT5 signaling. Cytokine 2018;110:397-403.

38. Yang X, Qiao D, Meyer K, et al. Signal transducers and activators of transcription mediate fibroblast growth factor-induced vascular endothelial morphogenesis. Cancer Res 2009;69:1668-77.

39. Dentelli P, Rosso A, Orso F, et al. microRNA-222 controls neovascularization by regulating signal transducer and activator of transcription 5A expression. Arterioscler Thromb Vasc Biol 2010;30:1562-8.

40. Chen H, Jing XY, Shen YJ, et al. Stat5-dependent cardioprotection in late remote ischaemia preconditioning. Cardiovasc Res 2018;114:679-89.

41. O'Neill S, Brault J, Stasia MJ, et al. Genetic disorders coupled to ROS deficiency. Redox Biol 2015;6:135-56.

42. Roth IL, Salamon P, Freund T, et al. Novel NCF2 Mutation Causing Chronic Granulomatous Disease. J Clin Immunol 2020;40:977-86.

43. Zhou S, Liu S, Liu X, et al. Bioinformatics Gene Analysis of Potential Biomarkers and Therapeutic Targets for Unstable Atherosclerotic Plaque-Related Stroke. J Mol Neurosci 2021;71:1031-45.

44. Chen M, Chen S, Yang D, et al. Weighted Gene Co- 
expression Network Analysis Identifies Crucial Genes Mediating Progression of Carotid Plaque. Front Physiol 2021;12:601952.

45. Misra P, Reddy PC, Shukla D, et al. In-stent stenosis: potential role of increased oxidative stress and glutathionelinked detoxification mechanisms. Angiology 2008;59:469-74.

46. Scarcello E, Lobysheva I, Bouzin C, et al. Endothelial dysfunction induced by hydroxyl radicals - the hidden face of biodegradable Fe-based materials for coronary stents. Mater Sci Eng C Mater Biol Appl 2020;112:110938.

47. Simhadri VR, Andersen JF, Calvo E, et al. Human CD300a binds to phosphatidylethanolamine and phosphatidylserine, and modulates the phagocytosis of dead cells. Blood 2012;119:2799-809.

48. Nakahashi-Oda C, Tahara-Hanaoka S, Shoji M, et al. Apoptotic cells suppress mast cell inflammatory responses via the CD300a immunoreceptor. J Exp Med 2012;209:1493-503.

49. Patrinos GP, Kollia P, Papadakis MN. Molecular diagnosis of inherited disorders: lessons from hemoglobinopathies. Hum Mutat 2005;26:399-412.

50. van den Akker E, Satchwell TJ, Pellegrin S, et al. Investigating the key membrane protein changes during in vitro erythropoiesis of protein 4.2 (-) cells (mutations Chartres 1 and 2). Haematologica 2010;95:1278-86.

51. Raess PW, Paessler ME, Bagg A, et al. $\alpha$-Hemoglobinstabilizing protein is a sensitive and specific marker of erythroid precursors. Am J Surg Pathol 2012;36:1538-47.

52. Dickson CF, Rich AM, D'Avigdor WM, et al. $\alpha$-Hemoglobin-stabilizing protein (AHSP) perturbs the proximal heme pocket of oxy- $\alpha$-hemoglobin and weakens the iron-oxygen bond. J Biol Chem 2013;288:1998620001.

53. Mollan TL, Yu X, Weiss MJ, et al. The role of alphahemoglobin stabilizing protein in redox chemistry, denaturation, and hemoglobin assembly. Antioxid Redox Signal 2010;12:219-31.

54. Arakawa T, Kobayashi-Yurugi T, Alguel Y, et al. Crystal structure of the anion exchanger domain of human

Cite this article as: Chen M, Dun Y, Zhang W, Liu S. Identification of differentially expressed genes associated with coronary in-stent restenosis by integrated bioinformatics approaches. Ann Palliat Med 2022;11(6):1940-1953. doi: 10.21037/ apm-21-2681 erythrocyte band 3. Science 2015;350:680-4.

55. Wang D, Song L, Shen L, et al. Mutational Characteristics of Causative Genes in Chinese Hereditary Spherocytosis Patients: a Report on Fourteen Cases and a Review of the Literature. Front Pharmacol 2021;12:644352.

56. Tsygankova OM, Keen JH. A unique role for clathrin light chain A in cell spreading and migration. J Cell Sci 2019;132:jcs224030.

57. Izem L, Bialkowska K, Pluskota E, et al. Plasminogeninduced foam cell formation by macrophages occurs through a histone 2B (H2B)-PAR1 pathway and requires integrity of clathrin-coated pits. J Thromb Haemost 2021;19:941-53.

58. Santiago JA, Potashkin JA. Blood Transcriptomic Metaanalysis Identifies Dysregulation of Hemoglobin and Iron Metabolism in Parkinson' Disease. Front Aging Neurosci 2017;9:73.

59. Vinchi F, Porto G, Simmelbauer A, et al. Atherosclerosis is aggravated by iron overload and ameliorated by dietary and pharmacological iron restriction. Eur Heart J 2020;41:2681-95.

60. Meng M, Liu S, Wang C, et al. Mass spectrum analysis of membrane proteins reveals that CASK, CD36 and EPB42 are differentially expressed in pancreatic adenocarcinoma. Oncol Lett 2020;20:376.

61. Bae SW, Berlth F, Jeong KY, et al. Glucose metabolic profiles evaluated by PET associated with molecular characteristic landscape of gastric cancer. Gastric Cancer 2021. [Epub ahead of print].

62. Hong SJ, Ahn CM, Kim BK, et al. Prospective randomized comparison of clinical and angiographic outcomes between everolimus-eluting vs. zotarolimus-eluting stents for treatment of coronary restenosis in drug-eluting stents: intravascular ultrasound volumetric analysis (RESTENTISR trial). Eur Heart J 2016;37:3409-18.

63. Włodarczak A, Rola P, Szudrowicz M, et al. Sex Differences in the Clinical Features and Outcomes of Patients with Acute Coronary Syndrome Treated with Two Generations (Absorb and Magmaris) of Bioresorbable Vascular Scaffolds. J Clin Med 2021;10:3768. 
A

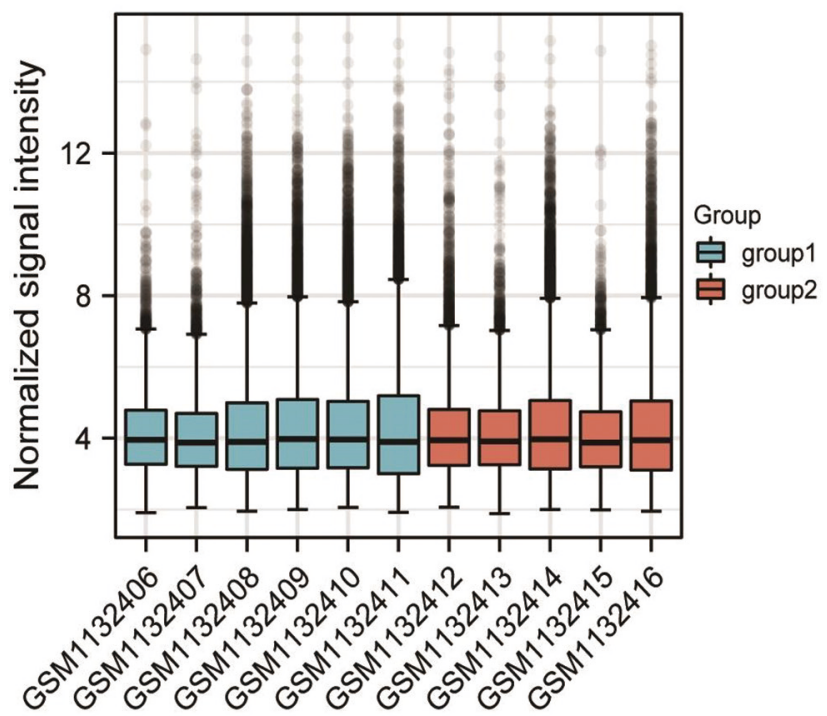

C

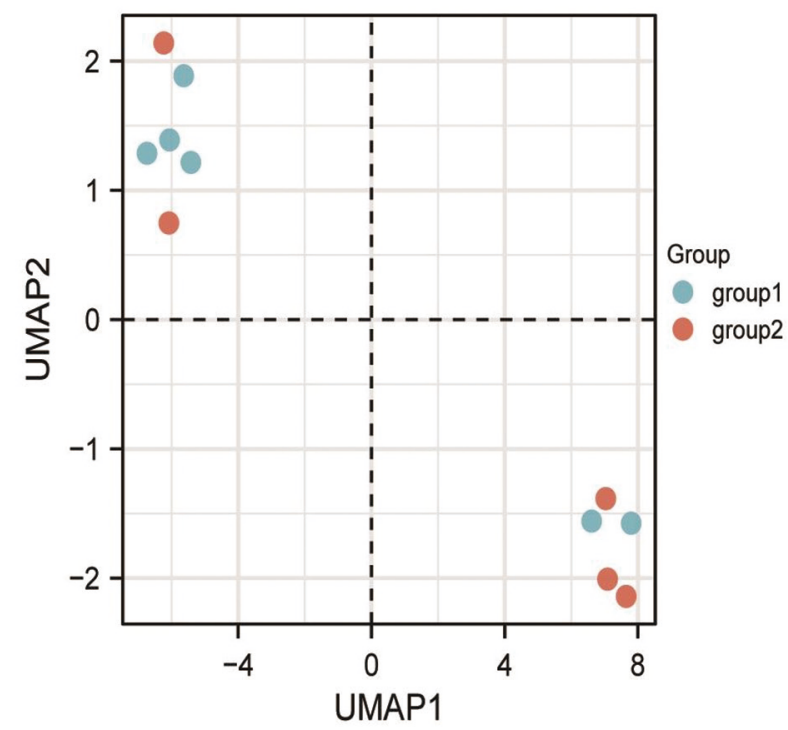

$\mathrm{B}$

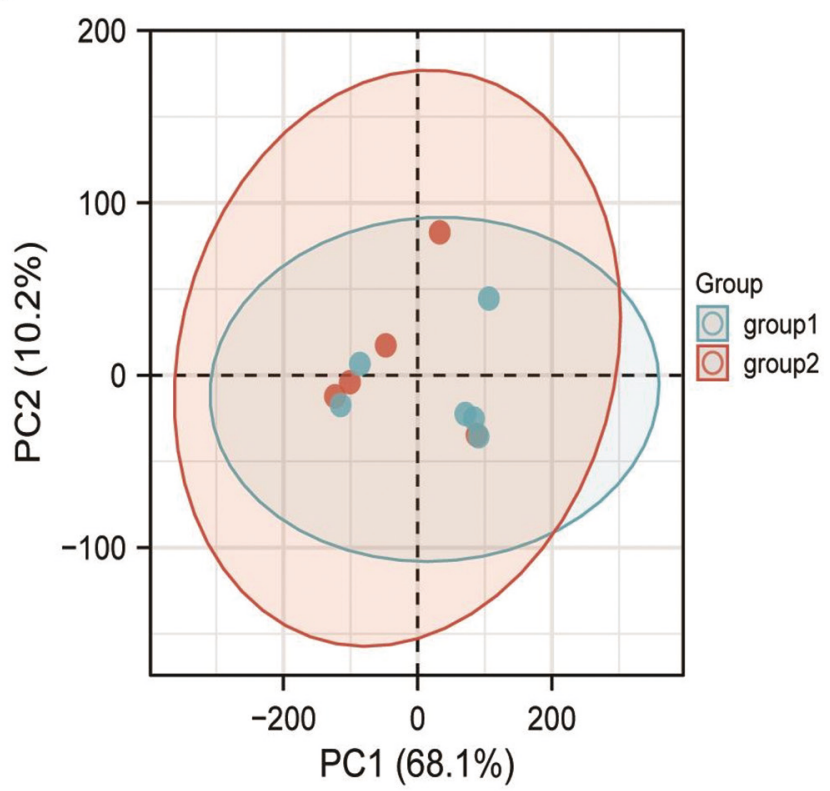

D

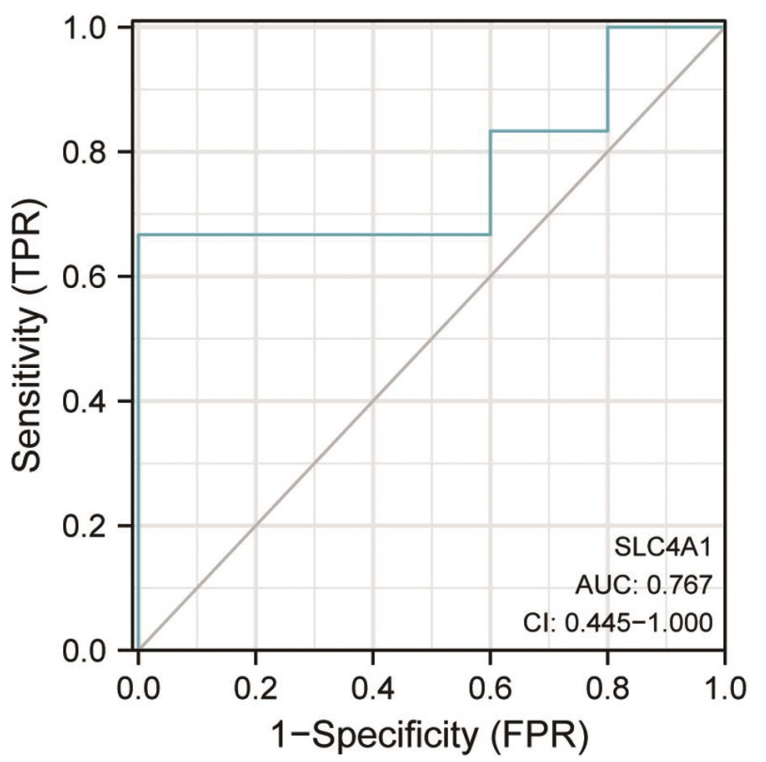

Figure S1 Box diagram (A); PCA diagram (B); UMAP diagram (C); The AUC in SLC4A1 (D). PCA, principal component analysis; UMAP, uniform manifold approximation and projection; AUC, area under the curve; SLC4A1, solute carrier family 4 member 1. 